\title{
¿ES POSIBLE MÁS Y MEJOR DEMOCRACIA? DEMOCRACIA COMO EMPODERAMIENTO POLÍTICO DEL CIUDADANO
}

\author{
IS IT POSSIBLE MORE AND BETTER DEMOCRACY? DEMOCRACY AS \\ POLITICAL CITIZEN EMPOWERMENT
}

\author{
Ángel Iglesias \\ Roberto-Luciano Barbeito \\ Universidad Rey Juan Carlos, Madrid. España/Spain \\ angel.iglesias@urjc.es \\ roberto.barbeito@gmail.com
}

Recibido/Received: 27/03/2014

Modificado/Modified: 30/05/2014

Aceptado/Accepted: 27/06/2014

\section{RESUMEN}

Este artículo expone que el significado primigenio del concepto de democracia ha sido distorsionado y todavía no hemos sido capaces de implantar diseños institucionales adecuados para ponerlo en práctica. El texto argumenta que el ideal democrático debe ser rescatado, y debe ser implementado mediante nuevos diseños institucionales que empoderen a los ciudadanos para participar directamente en los procesos políticos de toma de decisiones. El trabajo trata de identificar, asimismo, qué tipo de innovaciones democráticas sería factible desarrollar a partir de las aportaciones teóricas de destacados académicos. El texto muestra que las mayores dificultades para proceder a un proceso de profundización democrática son de carácter ideológico e intelectual.

\section{PALABRAS CLAVE}

Participación política, democracia deliberativa, democracia liberal, racionalidad económica, racionalidad comunicativa.

\section{SUMARIO}

1. Introducción. 2. El contexto de crisis de la democracia liberal. 3. Democracia y racionalidad económica. 4. ¿Es posible más y mejor democracia? 5. De la democracia liberal a la democracia deliberativa. 6. Consideraciones finales. Bibliografia.

\begin{abstract}
This article states that the original meaning of the concept of democracy has been distorted and we have not been able to apply appropriate institutional designs to develop it. The text argues that the democratic ideal must be rescued, and should be realized through new institutional designs that empower citizens to participate directly in political decision-making processes. The paper tries to identify, also what type of democratic innovations would be feasible to implement from the theoretical contributions of leading academics. The text shows that the greatest difficulties to carry out a process of democratic deepening are of ideological and intellectual character.
\end{abstract}

\section{KEYWORDS}

Political participation, deliberative democracy, liberal democracy, economic rationality, communicative rationality. 


\section{CONTENTS}

1. Introduction. 2. The context of crisis of liberal democracy. 3. Democracy and economic rationality. 4. Is it possible more and better democracy? 5. From liberal to deliberative democracy. 6. Concluding remarks. References.

\section{INTRODUCCIÓN}

Este trabajo está inspirado abiertamente en los planteamientos del profesor Fernando Quesada (2006), quien constata que no hay un único modelo de democracia, sin duda porque el concepto de democracia es de los más abstractos y polisémicos dentro de la filosofía política. Quesada expone que las dos concepciones cardinales de democracia están agotadas. La primera coincidiría con el mundo griego; la segunda, con la Ilustración. De acuerdo a Quesada, se hace preciso ahora identificar un tercer imaginario, que permita introducir nuevos tipos de hipótesis y sujetos democráticos, y que se adapte a las necesidades del mundo actual. Antes que explorar ese imperioso tercer imaginario, en este texto nos limitamos a defender, como hipótesis de partida, que las ideas originarias de democracia propias del primer y segundo imaginario siguen siendo válidas, pero han sido distorsionadas por un proyecto de modernización marcadamente economicista, excluyente y reduccionista. Según tal proyecto (que se exhibe como neutral, descriptivo, y hasta científico), el mundo social no es más que el simple producto del cálculo racional (instrumental y egoísta) de las utilidades individuales.

Este documento sostiene que el racionalismo instrumental, o economicismo, ha deformado el significado originario del concepto de democracia: la participación directa de los ciudadanos en los procesos de toma de decisiones (una exigencia moral, pero también práctica). El economicismo del libre mercado, en cambio, inhibe, y aun hace inconcebibles, diseños institucionales alternativos a los hoy existentes, impidiendo así la participación general en los asuntos comunes. Por eso argumentamos que es preciso se recobre la conciencia sobre la necesidad de rescatar el ideal democrático primigenio. A lo que añadimos un segundo punto: una vez retomada la conciencia sobre el deber cívico, y sobre la perentoriedad práctica de la participación popular para el fomento del bienestar social, deben pergeñarse diseños institucionales coherentes y efectivos. Esta vindicación no es contradictoria con el marco teórico de la democracia liberal. Antes bien, las instituciones representativas del paradigma liberal de democracia pueden, y deben, ser suplementadas por un conjunto de instituciones que empoderen a los ciudadanos para participar directamente en los procesos políticos de toma de decisiones. De no obrar así, habremos de enfrentarnos a un peligro mayúsculo: la manipulación de la democracia por parte de las élites, ya sean dirigentes políticos, corporaciones empresariales o demagogos populistas. En unas u otras manos, la autenticidad democrática quedará definitivamente diluida.

Un aspecto fundamental para que la democracia sea tal es que los ciudadanos soberanos dispongan de información amplia y contrastada, con el fin de que puedan tomar decisiones medidas y consecuentes. Cuando eso no es así, las perspectivas parciales de las élites se imponen con facilidad, y entonces se precipitan decisiones que pueden causar daño a grandes sectores de la población. Pues las élites no son las únicas depositarias de la racionalidad política. Como señaló John Dewey, la genuina racionalidad política es una cuestión de experimentación, pero que ha de ser llevada a cabo por públicos democráticos (amplios, numerosos, dispares), concebidos siempre como comunidades de ciudadanos. Para ejercer la 
democracia, es preciso que cada comunidad aporte sus perspectivas parciales y, entre todos, llegar a acuerdos pacíficos. Sin embargo, la perspectiva que se ha impuesto es la del liberal capitalismo, donde democracia y mercado, confundidos, aparecen como un modelo universal (Dewey, 1984). Este paradigma predica una democracia liberal mínima: partidos competitivos; oportunidades limitadas para la participación de unos pocos ciudadanos a través de grupos organizados con poca capacidad constitucional para poner limitaciones a la actividad del gobierno; aislamiento de la esfera económica del control democrático; y una acción política donde los actores definen y reconcilian los intereses en privado.

El liberal capitalismo no solo ha impuesto una visión limitada de la democracia. Muchos de los partícipes de esta visión empiezan a ver incluso con escepticismo, sino con manifiesta hostilidad, cualquier propuesta de mejora democrática. La propia democracia acaba siendo cuestionada. Estos enemigos de la democratización no son hoy fascistas, aristócratas, postulantes del "socialismo científico" u otros supuestos guardianes del bien común. Antes bien, operan fuerzas políticas y económicas más sutiles e insidiosas, parte nuclear de los poderes opacos (Gil Calvo, 2013), que difunden doctrinas hostiles para la democratización y la democracia. Estas doctrinas sugieren que "no hay alternativas" viables, y nos invitan a estar felices con "lo que hay", a no ir más allá. De este modo intentan inhibir cualquier atisbo de perfeccionamiento democrático. Por eso este texto acomete denunciar la lógica antidemocrática que reside dentro de la actual versión economicista de la democracia, así como identificar qué clase de innovaciones democráticas sería factible implementar en el corto plazo. En ambos casos, nos ampararemos en el análisis de las aportaciones teóricas de algunos distinguidos académicos, especialmente identificados con las diversas propuestas de democracia deliberativa. Podemos avanzar que las restricciones que frenan la profundización democrática son, ante todo, ideológicas e intelectuales, y son difundidas incluso por muchos pensadores que, si en algún momento consideraron positiva la implantación de la democracia, ahora impelen a frenar su desarrollo. Es preciso insistir que estas limitaciones antidemocráticas se asocian con una falaz, pero muy difundida, creencia: que la democracia liberal que tenemos (es decir, en un contexto económico capitalista) representa la cúspide de los logros democráticos a los que podemos aspirar, tal y como se proclama desde los poderes económicos y mediáticos, concentrados en clara connivencia con los núcleos del poder propiamente político. De ahí que proliferen las demandas de más gestión, y menos participación, bajo el supuesto de que deben gobernar los que realmente saben y tienen competencia para ello. Pero, como insistentemente advirtió Robert Dahl, padre del pluralismo político y una de las cumbres de la sociología política universal, el gobierno tecnocrático (o tutelaje basado en la calificación) "es probablemente la visión más engañosa jamás creada por los adversarios de la democracia" (Dahl, 1992:13). Pese a estas y otras advertencias, la idea fuerza de que la democracia ha llegado a la cúspide, de que no es posible más ni mejor democracia que la vigente, y de que ahora ya solo queda preocuparse por la gestión técnica eficaz de los recursos públicos, es predominante. El punto crítico de su escalada fue el desmantelamiento del bloque soviético y la crisis de confianza en que está inserta la otrora fuerte socialdemocracia occidental.

En este texto sugerimos que la democracia liberal (representativa) es viable, pero solo si se complementa con la deliberación, esto es, con fuertes dosis de participación directa. Vaya por delante que la deliberación no se plantea aquí como empoderamiento político de un genérico "pueblo" (power to the people), sino como empoderamiento político del ciudadano en cuanto individuo. Ello lleva implícito que hay que considerar el demos como la suma del empoderamiento político de cada individuo miembro de ese demos. Este planteamiento 
conlleva hacerse cargo también de otros dos conceptos clave en la filosofía política, cuales son los de autonomía y soberanía. Postulamos que ambos son susceptibles de hacerse operativos en el corto plazo dentro de las esferas públicas micro, esto es, en el nivel de la vida cotidiana del individuo (por ejemplo, el lugar de trabajo, las comunidades locales, las asociaciones voluntarias). Tampoco descartamos la implantación de la democracia deliberativa en otros ámbitos micro de la arena política, como los gobiernos locales, los barrios y los distritos de las grandes ciudades. Incluso es posible pensar que, en un estado más avanzado del tiempo y de la práctica participativa, pudiera extenderse a niveles macro del proceso de toma de decisiones colectivas. En todo caso, para que estas propuestas prosperen, es forzoso revisar el concepto de democracia, y es urgente asimismo identificar, y aprovechar, las posibilidades tecnológicas hoy disponibles. Nuestras hipótesis se argumentarán como sigue: En el primer apartado se resumen algunos de los elementos constitutivos de la crisis actual de la democracia. En el segundo apartado se aborda la cuestión de la preeminencia de la racionalidad económica como tecnología de la modernización. En el epígrafe tercero se discute acerca de la posibilidad de lograr más y mejor democracia. Finalmente, en el apartado cuarto, se plantea el que probablemente sea el tema más importante del trabajo, a saber, hasta qué punto y en qué condiciones sería posible la implantación de la democracia deliberativa.

\section{EL CONTEXTO DE CRISIS DE LA DEMOCRACIA LIBERAL}

La historia de la democracia ha sido una historia de traición a sus contenidos morales y, por tanto, a sus ideales, particularmente el más elemental: la participación igualitaria del ciudadano en el proceso político. La idea del gobierno del pueblo, o ideal del empoderamiento político popular, que prevaleció en las concepciones de la democracia propias de las sociedades pre-liberales, es ahora una noción problemática. Pero fue practicada con éxito en períodos cortos de la historia, siendo ejemplar el caso de la Atenas clásica. Cierto que la democracia ateniense radicó en la prosperidad económica y, sobre todo, en la ausencia de agudas desigualdades económicas entre los ciudadanos. Precisamente el reducido número de ciudadanos fue un factor decisivo de esa democracia, y la razón de ello es que excluía del demos al grueso de la población: mujeres, extranjeros, esclavos.

Más allá de la fehaciente democracia ateniense, el genuino ideal de gobierno del pueblo apenas ha superado las pruebas pergeñadas desde la filosofía política, y con un alcance muy limitado. Así, el célebre planteamiento rousseauniano de la democracia nunca ha sido puesto en práctica. Una importante causa de ello es que su proyecto estaba limitado a un pequeño cuerpo político de carácter agrario (Rousseau, 2004). En contraste, la visión leninista de una democracia del proletariado sí fue puesta en práctica, y a gran escala, pero produciendo, a la postre, un resultado opuesto al ideal democrático, con ausencia de contrapesos y de procedimientos democráticos de respeto a las minorías para resolver los conflictos. Y tampoco resolvió el problema crucial que pesa sobre la actual democracia liberal: la preeminencia de las élites políticas, económicas e intelectuales en el proceso de toma de decisiones.

Ciertamente la democracia liberal ha pervertido el ideal democrático primigenio. Es así porque este paradigma concibe la democracia como una mera estrategia de estabilización, puramente instrumental, de procura del orden social que conviene a las clases sociales más favorecidas. Desde el inicio de la Revolución Industrial, las clases propietarias sostenían que los estallidos sociales y los accesos revolucionarios habrían de evitarse, controlarse y 
desmantelarse. Bien organizadas, y con la ayuda de las élites intelectuales de clase media interesadas en proteger sus intereses frente a las clases proletarias que se alzaban en contra del estado liberal, dedicaron ímprobos esfuerzos a justificar que el buen funcionamiento del libre mercado requería estabilidad, para que los individuaos pudieran calcular los riesgos de sus decisiones económicas. Ello supuso modular la idea de democracia de tal modo que se la despojó de sus contenidos morales, deformándola hasta convertirla en un simple procedimiento para la toma de decisiones. Tal es la célebre, y muy restringida, noción de democracia que proporciona Joseph Schumpeter, cuando afirma que la democracia es simplemente un método no violento para la selección de líderes políticos que compiten entre sí por el voto de los ciudadanos (Schumpeter, 1996). Se trata de una concepción tan arraigada que es la que se facilita incluso en acreditados y vigentes manuales de ciencia política, como el de Josep Colomer (2001), o en revisiones tan ambiciosas del significado de la democracia como el que hace Giovanni Sartori (2003).

Alejados de aquel contexto, hoy consideramos conveniente recuperar la idea de soberanía propuesta por Rousseau en tanto que soberanía implica el ejercicio colectivo del poder de decisión por los ciudadanos. Pero con la diferencia de que, a nuestro juicio, los ciudadanos deben ser tomados como individuos. Siendo el individuo el punto de partida, la soberanía del pueblo sería la suma de las soberanías individuales de los ciudadanos que componen el demos. "Individualizar" la soberanía no significa divisibilidad ni tampoco contradice la propuesta del ginebrino según la cual la soberanía es indivisible. La individuación de la soberanía aquí patrocinada implica que el poder legislativo ha de ser distribuido igualitariamente en la sociedad. En congruencia, hay que facilitar asimismo la participación efectiva de cada individuo en los procesos de toma de decisiones colectivas. Curiosamente, este enfoque encaja con la importancia que la democracia liberal otorga al individuo y, al mismo tiempo, con la individuación de las estructuras tecnológicas. Además, la concomitante idea de autonomía política, de raíz kantiana, sería el estado de tener control sobre la propia situación dentro del marco de una comunidad política que es al tiempo una comunidad moral. El individuo, por mor de mantener su autonomía, estaría obligado a interactuar con su comunidad política, en condiciones de franca igualdad. La concepción de democracia como empoderamiento político del ciudadano que aquí se defiende deja de lado resulta compatible con las actuales relaciones de producción, pues no se requiere, de entrada, una reorganización social radical. No obstante, es una concepción que asume que estas relaciones de producción y los derechos de propiedad no deben interferir, ni mucho menos imponerse, a los principios de soberanía y autonomía políticas (García Santesmases, 1997). En consecuencia, el desarrollo de esta clase de democracia deliberativa requeriría limitar en cierta medida la libertad económica de las instituciones y relaciones económicas (particularmente, las fuerzas del mercado y, singularmente, los movimientos de las mercancías y del capital financiero).

El problema que subyace a la concepción liberal de la democracia es que se sustenta exclusivamente en el concepto de representación, Así, reduce la democracia al gobierno de los representantes elegidos. Esta concepción aparta políticamente al ciudadano y transfiere el poder legislativo y las decisiones públicas a los representantes (en realidad, una clase de elites políticas que alcanzan su estatus ganando elecciones). La idea del gobierno representativo en los estados liberal-democráticos se sustenta, de hecho, en la premisa de alejar a los ciudadanos de los asuntos de gobierno, de manera que el estado pueda ser instrumentalizado por las clases más pudientes, o los grupos de interés mejor organizados que buscan instrumentalizar al estado para sus objetivos socioeconómicos y políticos. La cuestión se centra en alcanzar el poder por la vía de elecciones "libres" y "competitivas", no 
para empoderar al ciudadano, sino para desempoderarle, eso sí, mediante elecciones competitivas, en favor del triunfo irreversible del capitalismo.

La instrumentalización que de la democracia hacen ciertos grupos sociales es congruente con el meollo de las economías contemporáneas de mercado. Las decisiones se legitiman a partir de la supuesta racionalidad de los individuos, esto es, el cálculo y defensa del propio y solo interés. Y así es que, desde las ciencias sociales, las teorías de la elección racional han venido proveyendo un respaldo teórico para el diseño de políticas públicas que reproducen este tipo de individualismo. Pero esta clase de individualismo, que resulta funcional, en principio, para la actividad económica capitalista (la de los grupos que concentran los recursos productivos), es, sin embargo, mortal para la política democrática.

\subsection{Los defensores del triunfo del liberalismo económico}

El triunfo irreversible del liberalismo económico, y de la democracia capitalista, aparece anunciado por Francis Fukuyama en su artículo "El fin de la Historia" (1989) y su posterior libro El fin de la historia y el último hombre (Fukuyama, 1992). Esta tesis se formula ante el colapso de la Unión Soviética, y defiende que el marxismo no tiene nada que ofrecer a los países subdesarrollados en términos de bienestar. Con el definitivo descrédito y desaparición de los regímenes comunistas desparece un modelo alternativo. Es oportuno indicar que las previsiones de Fukuyama acerca del destino de la historia tienen un sorprendente parecido con la teoría funcionalista del desarrollo, o de la modernización, formulada por científicos sociales estadounidenses en plena Guerra Fría. Ese enfoque fue un claro apoyo para la política del gobierno de los Estados Unidos y para las agencias de ayuda multilateral. Entre otras afirmaciones, sostiene que las etapas del crecimiento económico culminan en un sistema económico capitalista liberal con las características políticas de las actuales democracias occidentales (Rostow, 1990). Y así Fukuyama, lo mismo que los teóricos de la modernización, justifica una determinada visión de la evolución social, de connotaciones hegelianas, a modo de progreso lineal ineludible. Esta imagen se ha proyectado también en la literatura sobre los procesos de democratización, que insiste en que la democracia capitalista es la única opción (Huntington, 1996). La preeminencia de estos autores en los debates públicos y académicos conduce así a que sean los defensores de la (limitadísima) democracia capitalista quienes ostenten el monopolio mediático de las ideas acerca de la democracia.

Pese a lo dicho, el capitalismo ha sido un aliado de la democracia liberal en el momento de su establecimiento. En el momento presente, sin embargo, el capitalismo del libre mercado aplica imponentes restricciones al gobierno democrático. El control democrático popular es disfuncional a los intereses económicos de los grupos privilegiados y eso marca un tope para el desarrollo de las democracias liberales existentes. Hay muchos modos a través de los cuales los intereses dominantes del mercado restringen la democracia. Así, por ejemplo, en los sistemas de mercado los gobiernos deben estimular la inversión de las empresas privadas. Si las empresas no invierten, la desaceleración de la actividad económica castiga a los gobiernos de dos maneras. De una parte, los ingresos fiscales caen, y se reducen los recursos disponibles para los programas de gobierno. De otra parte, disminuyen los bienes en términos de empleo e ingresos y, como corolario, se pone en peligro la popularidad $\mathrm{y}$, en última instancia, la legitimidad del gobierno. De manera que los gobiernos no se atreven a perseguir con sus políticas públicas impactos negativos en la rentabilidad de los negocios privados, por temor a precipitar una huelga de capital. Estas decisiones pueden evitarse sólo confiando en fuentes de financiación fuera del Estado, tales como la deuda externa, pero las condiciones de dicha asistencia financiera casi siempre apuntan en la misma dirección que las restricciones del mercado. La presencia de todas estas limitaciones significa 
que no es al parlamento o a la opinión pública a quien tiene que rendir cuentas la acción de gobierno, sino a los mercados, esto es, a las instituciones financieras transnacionales convertidas en acreedores de los gobiernos. Los intereses de los negocios privados se imponen así a los intereses públicos, o comunes. Como la democracia, a través de la activa participación de los ciudadanos, puede interferir en las expectativas de negocio, quienes los despliegan tenderán a minimizar la democracia. De este modo, la presunta soberanía de la ciudadanía democrática se jibariza frente al capital. Así ceñida, la democracia se convierte en un mero procedimiento donde el proceso político se reduce a las elecciones, decretos ejecutivos y esporádicos estallidos de protestas, y en donde todo el poder del estado se concentra en el ejecutivo (Przeworski, 1991).

El pesimista diagnóstico respecto a las posibilidades de la democracia capitalista exhibido por Przeworski no es aislado. Lo comparten autores tan notorios como Polanyi (1989), Elster (1990) u Offe (1987). Según estos, el ideal democrático no es sostenible si se basa en la convicción de que los ciudadanos actúan políticamente pensando solo en su propia ganancia material y en el corto plazo; es decir, de manera económicamente racional. El problema de fondo es el predominio de la racionalidad económica en el ámbito político. Una mercantilización tan alocada, tan miope, que, en el largo plazo, socava incluso las condiciones políticas que se requieren para su progreso. Mas, si el mercado capitalista impone tales restricciones a la democracia, hay que resolver una intrigante pegunta: ¿cómo fue posible la instauración del Estado del bienestar, la alteración más profunda y conscientemente diseñada en el marco de la economía política capitalista liberal? La respuesta es que el Estado del bienestar surge no tanto como un producto de decisiones voluntarias en pos de la justicia social, sino como un complemento necesario a la economía capitalista. Quizás, la supervivencia misma del orden económico capitalista es debida a la reducción de algunos de sus síntomas negativos (desempleo, pobreza, inseguridad ingresos, alienación, etc.) por el Estado del bienestar de inspiración keynesiana (o del New Deal promovido por Franklin D. Roosevelt en los EEUU para superar la desigualdad que condujo a la Gran Depresión). Y es que el Estado del bienestar surgió de una necesidad estructural en la economía política nacional e internacional: hacer frente a la pujanza del bloque soviético y las revoluciones obreras, particularmente tras la experiencia traumática de la II Guerra Mundial (Judt, 2010). Por añadidura, el Estado de Bienestar keynesiano facilitó la extensión efectiva de la democracia representativa a la clase obrera organizada y, precisamente por eso, su actual desmantelamiento implica el reforzamiento de las limitaciones para la innovación democrática.

\subsection{La función de la ideología}

La ideología ayuda a apuntalar todo sistema y la construcción del liberalismo económico (ideología, tanto o más que ciencia), ha sido extraordinariamente eficaz para asimilar y desarmar a los potenciales críticos del sistema, incluyendo a los demócratas. Aunque triunfante, la ideología del capitalismo democrático liberal no ha alcanzado la hegemonía global. Curiosamente, compite aún competencia con regímenes autoritarios cuya política económica sí ha adoptado, no obstante, el núcleo de lo que podría denominarse capitalismo descontrolado (Rusia y China, por ejemplo). Pero donde no hay "competencia" es entre distintas ideologías democráticas, a partir de la cual se vislumbren perspectivas de innovación democrática. Tal vez la falta de esta "competencia" contribuye al evidente empobrecimiento de la democracia. La democracia está tan herida, tan huérfana, en el capitalismo de libre mercado, que un pesimista radical podría concluir que democracia y 
capitalismo son incompatibles. Así es que habría que esperar a un futuro postcapitalista para dibujar otra idea de democracia, requiriéndose, en este caso, la existencia de un nuevo sujeto que hiciese desaparecer el capitalismo. Una catástrofe ecológica sería, sin duda, un buen candidato para ejercer de sujeto democratizador, puesto que, en su procura desaforada de crecimiento, sin límites ni reglas, el capitalismo no sería sostenible en un medio ecológico finito (Naredo, 2010). Claro que, incluso si finalmente llegara a producirse un irreversible deterioro ecológico u otra crisis terminal del capitalismo, cualquier resultado democrático dependería de la capacidad de la sociedad para negociar y gestionar la transición a una verdadera democracia. Pero esa transición sería deudora, a su vez, del grado en que la democracia pueda ser alimentada y protegida contra las consecuencias del capitalismo aquí y ahora. Y puesto que pensamos que ese es el problema central del tiempo que nos toca vivir en lo que concierne a la democracia, debemos aportar algunas conclusiones positivas con respecto a las posibilidades de la democracia y la democratización. Por ello, como alternativa se sugiere la posibilidad de indagar de qué modo la democracia puede ser reconceptualizada y fortalecida frente a las poderosas fuerzas antidemocráticas. En este punto conviene recordar que, como han puesto de manifiesto algunos autores (así, Offe, 1987) el capitalismo no está exento de contradicciones, siendo una de ellas la contradicción entre la acumulación y legitimación. Desde luego, los estados pueden ser capaces de arreglárselas sin modificar los fundamentos de su estructura interna y su relación con su sociedad civil (aunque creemos que esto, en última instancia, sería improbable en el contexto del imperativo ecológico). Alternativamente, las contradicciones y la confusión generada a partir de ellas pueden ser aprovechadas por aquellos cuyo interés fundamental es la innovación política y la propuesta de diferentes tipos de medidas de política económica. El tipo de sujeto que el capitalismo democrático liberal produce no está tampoco exento de contradicciones, aunque la penetración de la racionalidad económica en el comportamiento político de los individuos devasta la política democrática al ser esa racionalidad un enemigo de la democratización.

La victoria de la democracia capitalista mundial se sustenta en la comparación de los méritos prácticos de diferentes tipos de sistemas políticos y económicos, particularmente con relación al socialismo soviético. Aun así, la ideología es la que resulta en última instancia decisiva. Las ideas humanas no afloran gratuitamente de los contextos sociales, y el supuesto implícito es que es que las ideas impregnan las instituciones y las prácticas sociales. En este contexto, la tesis de Fukuyama del final de la historia se basó en el idealismo hegeliano. Las ideas no son actos aislados de creatividad pergeñada por filósofos o estadistas; constituyen un flujo y un patrón a través del tiempo al cual otorgan significados. Y para Fukuyama (1992), el "mecanismo" que ahora domina la historia consiste en la razón científica desarrollada puesta al servicio de la satisfacción de los deseos humanos a través del capitalismo. En estas condiciones, el capitalismo sería un sistema económico altamente funcional y la política democrática liberal su necesario complemento.

Lejos de las presunciones de Fukuyama, no solo las cualidades intrínsecas de la democracia capitalista, o su consistencia con la naturaleza humana, eliminan otras alternativas. Simplemente acontece que no tenemos ninguna otra idea sobre lo que podría funcionar tan bien o mejor. A primera vista parece que la victoria de una ideología sobre las demás, la de democracia capitalista sin competidores plausibles, es racional y, por tanto, debería aceptarse este hecho Sin embargo, cuando una ideología vence a su oposición y asegura el predominio político se debe sospechar que existen fuerzas e intereses no sujetas al juicio racional. Tales fuerzas incluirían la difusión de haberes sustentados en racionalidades parciales, y la aplicación de las ideas y el ejercicio del poder político a su servicio. 
De manera que el triunfo de la democracia capitalista se sustenta en un juicio racional provisional, aceptado, eso sí, por un gran número de personas. Ese discernimiento proclama que la democracia capitalista es, por el momento, el mejor sistema disponible. Pero se trata de una visión simplista respecto el sentido originario de la democracia liberal, aunque sin duda es la dominante. Por usar el lenguaje popularizado por Michael Foucault (1980), la democracia capitalista es un discurso que genera una determinada identidad. Para Foucault, un discurso es un modo de aprehender el mundo; es lo que permite a las personas dar sentido al mundo que les rodea. Los discursos no son neutrales; siempre encarnan los privilegios de determinados individuos y, entonces, la historia es también una sucesión de represiones. La represión se logra mediante un discurso que presenta como universales cuestiones que son, en realidad, completamente convencionales, socialmente construidas, pero que han de parecer naturales. Además, es muy difícil escapar de los discursos, porque poseen sus propias normas de verdad y racionalidad. De ahí que, para Foucault, no hay separación entre verdad y poder. Aplicando esta reflexión, la democracia capitalista no es un sistema superior en comparación con sus competidores, ni universalmente elegida como la mejor opción. En cambio, constituye a los individuos de tal manera que les incapacita para elegir cualquier otra cosa. Por lo tanto, si la democracia capitalista ha ganado la lucha global en el plano ideológico, es porque ha sido extraordinariamente exitosa al proporcionar a la población criterios que le llevan a desistir de sistemas alternativos. Basándose en estos criterios, el capitalismo liberal siempre gana, pues incluyen la prosperidad material, la paz social, la libertad negativa (de restricción de la libertad), la igualdad de oportunidades y la competencia política. Quedan así marginadas otras medidas alternativas, como la conservación de las tradiciones sociales, la armonía ecológica, la satisfacción espiritual, la solidaridad y la libertad positiva (libertad para desarrollar las capacidades personales en la asociación política). Marginadas, pero no anuladas, pues hay que reconocer la existencia de grupos (sociales y académicos) que sí vindican estas otras medidas. Eso nos hace pensar que, contradiciendo en este punto a Foucault, por mucho dominio que alcancen los discursos particulares, siempre es posible presentar alternativas al orden económico y político imperante.

De manera que podemos afirmar que el vigente sistema político y económico (la actual democracia capitalista) combina una rigidez en su estructura esencial con una flexibilidad en su justificación ideológica. Su estructura de base se resiste a cambiar, ya que, automáticamente, se castigan las innovaciones institucionales que amenazan la confianza de los mercados. Pero su ideología es flexible en ese liberalismo que puede parecer sinónimo de lo que es bueno, justo y correcto. Esta flexibilidad llega a ser comprensible una vez que la democracia liberal capitalista es entendida como el discurso de nuestros tiempos, que ha sido eficaz en la producción de las normas de su propio modelo de razonamiento (de juicio, diríamos en términos kantianos). El liberalismo ha sido también bastante bueno en producir sus propios críticos. Así, ideólogos y filósofos liberales no siempre participan en la celebración acrítica del estatus quo. También avanzan principios poco "realistas" de los cuales las sociedades existentes adolecen. Estos principios son muy variados, y van desde la cuasi científica "sociedad abierta" de experimentación política y debate libre, propuesta por Karl Popper (1992), a los principios igualitarios de justicia avanzados por John Rawls (2006), hasta llegar al conjunto de derechos individuales agresivamente libertarios avalados por Robert Nozick (1974). Hay que reconocer, no obstante, que el liberalismo ha dado también cumplidas muestras de asimilar a los críticos que operan desde fuera de su campo. En consecuencia, los partidos socialdemócratas que alguna vez llevaban en sus idearios la 
transformación del capitalismo, ahora se muestran satisfechos con no aspirar más que a una razonable gestión, suavizando algunas de las consecuencias más ásperas del libre mercado. Su compromiso con la democracia se ha traducido en apoyo a la democracia liberal, pero con exclusión de la democracia económica, aspecto indispensable para poder ejercer la igualdad política que presupone la democracia genuina (Dahl, 1992). Incluso los demócratas radicales, tal y como argumenta Barber (2004), se conforman con elevar la calidad y cantidad del debate político liberal. Aun quienes afirman el ideal de comunidad para contrastarlo con el individualismo liberal, sostienen, sin embargo, que el liberalismo puede acomodar la idea de comunidad bastante bien. Y hasta notorios autores posmodernos, que comienzan con una moción a la totalidad de la sociedad occidental, terminan celebrando la expresión pluralista de las diferencias permitidas por la democracia liberal (Rorty, 1989).

La aparente apertura a la crítica, por parte de la ideología liberal, resulta muy decorosa, pero su efecto neto es asimilar a los potenciales críticos de la democracia capitalista sin cambiar nada en el camino, particularmente del orden político y económico y sus núcleos de poder. La victoria global de la democracia capitalista se debe así a la existencia de una estructura que se auto-reproduce, combinada con un discurso que constituye a individuos en ciertos aspectos, y que es lo suficientemente flexible como para acomodar y desarmar a los críticos. Pero sería erróneo concluir en este punto que la democracia capitalista es inexpugnable. La tarea pendiente es localizar las posibilidades de innovación democrática frente a esas limitaciones estructurales e ideológicas. De ello nos ocuparemos en epígrafes posteriores, no sin antes analizar la principal restricción ideológica que, informada por la racionalidad económica, se presenta como hegemónica para, después, en consonancia con Habermas, quien viene de una línea crítica que comienza con Marx, proyectar algunas alternativas no radicales al liberalismo, pero que incluyan la participación general, la virtud cívica y la responsabilidad pública.

\section{DEMOCRACIA Y RACIONALIDAD ECONÓMICA}

El pensamiento económico neoclásico se sostiene en la idea de que el ser humano es esencialmente racional y egoísta. Racional en el sentido instrumental de ser capaz de identificar los mejores medios para optimizar la consecución de sus fines en forma de bienes. Este modelo no es exclusivo de la economía, pues se aplica asimismo a la política, la cultura, las relaciones familiares, la amistad o la guerra, por poner ejemplos dispares.

La racionalidad económica es, en cierto modo, una expresión extrema de las tendencias generales hacia la racionalización, puestas de manifiesto a principios del siglo XX por Max Weber, así como hacia la mercantilización de toda la vida social, señalada antes por Marx. Habermas (1998) se refiere a estas tendencias como la "colonización del mundo de la vida" por el dinero y el poder, donde la interacción comunicativa cotidiana es desplazada y subordinada al pensamiento comercial, guiado por la ganancia monetaria, y al pensamiento burocrático, preocupado por la consecución y mantenimiento del poder político. De estos dos aspectos de la racionalización, es ahora la comercialización, o mercantilización, la que se muestra hegemónica.

\subsection{El desarrollo histórico de la racionalidad económica}

Para mostrar las repercusiones sustanciales de la racionalidad económica en la democracia contemporánea es conveniente realizar una incursión histórica, aunque sea de manera muy breve. Veremos así que no hay nada de natural, ni de universal, en la idea del egoísmo 
racional aplicado a la vida social, económica o política. Por lo demás, el recorrido histórico mostrará que, si bien es posible que alguna vez la racionalidad económica fue buena para la democracia, ahora ha dejado de serlo.

La idea de que los seres humanos son esencialmente racionales es el gozne sobre el que gira el pensamiento económico, de manera que la racionalidad económica se sustenta en la idea de que los seres humanos son racionales y egoístas. Son racionales en el sentido de que idean y seleccionan los mejores medios para obtener los resultados deseados, y son egoístas en el sentido de que el fin primordial es el interés propio. Esta noción de la racionalidad se aplicó en origen al análisis económico, pero hay una tendencia creciente a aplicar este modelo a todo ámbito social, como la política, cultura, amistad, guerra y la familia, y no solo al de las transacciones económicas. Tal racionalismo económico, de origen angloamericano, ha sido exportado toda clase de asociaciones y aun a las organizaciones internacionales, controladas crecientemente por economistas y grupos de interés. Así la Agencia de los Estados Unidos para la Cooperación Internacional, que intenta convencer a otros países para que se hagan cargo de que todos los males proceden del gobierno político y de la gestión pública de los servicios fundamentales, y que la única salvación posible está en el mercado y la propiedad privada.

Es justo reconocer que el apóstol del liberalismo clásico, Adam Smith, señaló, al reflexionar sobre la riqueza de las naciones, cómo los individuos que persiguen su propia ventaja a la postre están promocionando los intereses comunes (Smith, 1958). Sin embargo, Smith, como su contemporáneo David Hume, tratan la racionalidad económica solo como una característica contingente de la más compleja interacción humana. La racionalidad económica no se impuso hasta el surgimiento de lo que Smith llamaba la sociedad comercial, la cual progresivamente se ha convertido en la sociedad capitalista. Aún así, este desarrollo no penetra en todos los ámbitos de la vida de manera uniforme. Antes del desarrollo capitalista predominaron otras motivaciones que incluían el dolor, la vergüenza, la fama, venganza, la identificación con un grupo o un líder, la ira, la envidia o el honor. Fue precisamente por la naturaleza destructiva de muchas de estas motivaciones que Smith y Hume dieron la bienvenida al desarrollo de una sociedad sustentada en valores mercantiles, en criterios objetivables, menos pasionales, en apariencia menos arbitrarios, más meritocráticos. Incluso Voltaire ofreció la procura del propio interés como alternativa a la idea cristiana de abnegación. Según él, asumir la defensa de los intereses propios permite incorporarse al mundo, preocupándose por uno mismo y, en consecuencia, por los demás, puesto que el bienestar de uno depende del de quienes le rodean.

La presumida autonomía de lo económico, que se pretende clave unificadora de la realidad, implica una desconexión profunda con otros ámbitos sociales. Este entramado de significados fue construido históricamente a partir de la dogmática de los fisiócratas, que establecían las categorías fundamentales (riqueza, crecimiento, trabajo, valor de cambio, entre otras) constituyéndolas en un Vorgriff, una predisponibilidad que delimita el posterior campo de estudio a la luz de una precognición, que suele asumirse como evidente. Las categorías de la fisiocracia perseguían una caracterización homogeneizante. Posteriormente, a través del pensamiento mecanicista, fueron convertidas en agregados capaces de ser cuantificados y exactificados mediante una misma red conceptual. Debido a este mar de fondo, el paréntesis keynesiano fue pronto fagocitado por el pensamiento monetarista, abandonando así los economistas la preocupación por la producción, y volcándose en el consumo y las finanzas. La riqueza inmobiliaria se transforma entonces en mobiliaria 
(Naredo, 2010), y los sujetos, atomizados, pierden conciencia del conjunto, y quedan cegados por la mera búsqueda de la (supuesta) utilidad particular.

\subsection{De Adam Smith a las teorías de la elección racional}

Históricamente, el egoísmo, y con él la sociedad mercantil que el capitalismo apuntaló, tuvo un efecto positivo para la consolidación de la democracia liberal. La universalización del interés propio como criterio de actuación para todos los individuos era una idea igualitaria y democrática, pues todo el mundo, y no sólo los poderosos, príncipes o papas, tenían intereses, $\mathrm{y}$, por tanto, todo individuo era digno de perseguir sus propios intereses y de exigir que se le favorecieran. Hume y Smith defendían esta universalización, incluso en contradicción con otras motivaciones, siempre y cuando los inevitables conflictos se resolvieran por medios democráticos. El ascendente aristocrático ya no sería la única voz autorizada para hablar en nombre del bien común. Se da por hecho que los aristócratas, como el resto de la gente, defienden sus particulares intereses.

El mayor impulso hacia la democracia dentro del capitalismo procede, sin embargo, del ascenso de la clase obrera. La democracia, en cuanto que extensión de los derechos de participación, es afín a los intereses del proletariado. Esperanzado en la posibilidad del progreso de la igualdad y del bienestar material, confió la consolidación democrática dentro del marco capitalista gobernado por la racionalidad económica. Justo al contrario de lo que ocurre ahora, cuando el desarrollo salvaje de la racionalidad económica está destruyendo la democracia. Por cierto que esta deriva fue anticipada por Smith, quien estaba convencido de que ciertas proclamas de comerciantes y fabricantes se utilizaban para tratar de garantizar la protección del gobierno contra la competencia, y así aumentar las ganancias jugando con ventaja.

Pero lo que Adam Smith reducía al ámbito del mercado, los posteriores y más próximos teóricos de la Escuela de la Elección Racional (Public Choice) lo amplían al ámbito político, de modo que sostienen que los individuos son económicamente racionales y egoístas en las dos esferas, que se hacen equivalentes. Algunos miembros de esta escuela de pensamiento, en particular James Buchanan, Gordon Tullock y sus colegas, comienzan con un pronunciado sesgo hacia el libre mercado y la sospecha general hacia todo lo que hagan los gobiernos (Buchanan y Tullock, 1993). Los promotores de la elección racional defienden una supuesta objetividad, afirmando que de ella se pueden derivar consecuencias para explicar y predecir el comportamiento político de los actores. Alegan, además, que las propuestas de la elección racional son de carácter totalmente positivo, completamente científicas y libres de valores. Estas teorías han descrito así con todo detalle los efectos nefastos de los individuos económicamente racionales persiguiendo ventajas a través de mecanismos políticos. Por ejemplo, el teorema de Arrow, uno de los constructos más fuertes de estas teorías, explica el comportamiento, con un alto nivel de abstracción, intentando demostrar la imposibilidad de diseñar mecanismos de decisión colectiva satisfactoria que no degeneren en la dictadura o en la manipulación de las agendas. Este autor fue pionero en la especialidad de las teorías de la elección racional que explora las propiedades de los distintos instrumentos políticos, tales como los sistemas de votación, que las sociedades pueden utilizar para agregar las preferencias de sus miembros que permitan llegar a decisiones para la sociedad en su conjunto. Sus teorías han venido a demostrar que todos los mecanismos de decisión colectiva se caracterizan por preferencias cíclicas y otras paradojas, de manera que es imposible mantener coherencia ni moral alguna. En presencia de las mayorías cíclicas, la alternativa elegida depende exclusivamente de las reglas de agregación del mecanismo político más a mano, y no puede justificarse en términos más generales. 
Así las cosas, aquellos que tienen el poder de manipular las reglas y las agendas cobran una enorme ventaja, capaz de asegurar que la alternativa de su preferencia sea la elegida. Todos pueden ser manipulados, y todos pueden ser el objetivo de un comportamiento estratégico. Los representantes de las teorías de la elección racional han desarrollado las críticas de muchos otros tipos de acuerdos políticos. Entre ellos, Niskanen considera a la burocracia como un escenario en el cual los burócratas tienen una tendencia inevitable a maximizar sus presupuestos, de modo que, para él, los burócratas son tan egoístas y racionales como cualquier otro agente. Persigue el avance de su carrera profesional, a la vez que mayores ingresos y prestigio, factores todos que resultan correlacionados positivamente con el tamaño del presupuesto de su unidad administrativa (Niskanen, 1974). Este análisis se vio refrendado por la política de Estados Unidos en la década de los ochenta del siglo pasado, y no es de extrañar que se convirtiera en presidente del Consejo de Asesores Económicos del presidente Reagan. Su visión ayudó asimismo a legitimar sustanciosos recortes del presupuesto general, señalando que los presupuestos públicos siempre serán demasiado elevados, y que los recortes se pueden llevar a efecto sin el más mínimo deterioro del servicio prestado. Con todo, los teóricos de la elección racional dibujan un Leviatán fuera de control, crecido hasta el punto de crear demandas para sus propios servicios (por ejemplo, el comportamiento electoral de los burócratas, que se decantarían por la elección de los políticos que prometen mantener o incrementar la financiación de los programas públicos). En este orden de cosas, la política se ha de interpretar como un juego de suma negativa en el cual los costos de las acciones, principalmente a los contribuyentes y consumidores, siempre superan los beneficios particulares de los actores políticos que están interesados en ellos mismos. Además, la política es también vista aquí como un juego intrínsecamente irresponsable, pues todos actores buscan los beneficios para sí mismos, al tiempo que imponen los costes a los demás. Por lo tanto, la elección racional construye la imagen de un hombre racional actuando en una sociedad irracional. Toma como universal el egoísmo racional según lo dado $\mathrm{y}$, consecuentemente, recomienda diseños institucionales para aprovechar bien este comportamiento común. No son otros que los mercados libres. Sugieren, como corolario, que se confien las funciones públicas al sector privado, bien mediante privatizaciones, bien mediante la gestión privada de los servicios públicos. Así, por ejemplo, en 1989, el gobierno de Thatcher, en el Reino Unido, al ver que era políticamente inviable la privatización del Servicio Nacional de Salud, determinó introducir la competencia dentro del sistema (financiado por el gobierno). La privatización y la creación de mercados internos dentro de lo público se convierten así en los mantras para la reorganización de las actividades gubernamentales. Pero incluso con estas medidas la política no puede ser eliminada completamente. Ante ello, los teóricos de la elección racional se deslizan hacia el nivel del análisis constitucional con la esperanza de identificar las modificaciones constitucionales a partir de las cuales se podría aprovechar el comportamiento de los actores económicamente racionales para la obtención de beneficios colectivos (un elocuente ejemplo sería la reforma del artículo 135 de la Constitución española, en 2011). La elección racional destinada a este terreno se conoce como Economía Política Constitucional. Sus postulantes trazan una distinción marcada entre las decisiones colectivas a la hora de diseñar las normas constitucionales como marco de convivencia, proceso que podría ser racional, y las convocatorias electorales, que son racionales en la medida que las decisiones ya han sido encuadradas en la etapa de diseño institucional. De tal manera que lo que se propugna es que las constituciones en cuestión especifiquen las reglas de votación, de separación de poderes, la autoridad relativa de diferentes ramas del gobierno, limitaciones en el alcance de los 
gobiernos, el dominio adecuado de diferentes tipos de derechos $\mathrm{y}$, también, los niveles tolerables de déficit presupuestario o de tipos impositivos.

Este modo de pensar deja de lado cualquier idea de solidaridad, cualquier conciencia de cooperación. Así, Claus Offe (1987) ya advertía de la pérdida generalizada de apoyo para el Estado de Bienestar a partir de mediados de 1970 en muchos países, y que es ilustrativo del calado del discurso en favor del mercado. La gente ya no considera el bienestar como una expresión de recíproco interés común, una protección colectiva ante las contingencias de la vida, sino como un conjunto de programas que pueden ser apoyados o no en función de los cálculos individuales, de lo que convenga a cada cual en cada momento. Pero, tal y como señala el mismo autor, el cálculo a corto plazo de los costes y beneficios no es inherente a la naturaleza humana ni, mucho menos, una norma universal de acción racional; por el contrario, es el producto de la desintegración y descomposición de las condiciones culturales y estructurales que modulan tales orientaciones utilitarias (Offe, 1987). Por añadidura, podemos argumentar nosotros que el interés individual a corto puede ser contradictorio con el interés individual a largo plazo. En todo caso, la disminución de la solidaridad y el aumento concomitante del comportamiento del calculador referido por Offe se refuerzan por la experiencia individual, donde la lógica del mercado entra cada vez en más ámbitos de la vida cotidiana (incluso en los íntimos). En el caso de los mercados, el empresario, como reacción a una decisión pública, puede actuar deslocalizando su negocio (ciertamente eso es posible mientras el poder político lo permita, pues en sus manos estaría también el no admitirlo).

En la política democrática, la respuesta adecuada incluye dar voz a las quejas. Sin embargo, los individuos que cada vez están más afectados por la lógica del mercado son los más propensos a ser criaturas de salida en lugar de voz, por manejar los términos de Hirschman (1970). Pero la salida deteriora la vía democrática. Los efectos de la difusión de los mercados pueden intensificarse por la difusión del análisis de elección pública. La solución aquí es hacer hincapié en la contingencia de estas predicciones, racionalidades alternativas que podrían negar las predicciones y las instituciones que podrían encarnar estas racionalidades. Esta solución requiere salir de las lógicas de la elección racional e ir más allá de la racionalidad económica, sobre todo cuando existen evidencias de que sus propios defensores violan la hipótesis de elección pública en muchos de sus comportamientos, por no actuar en términos instrumentalmente racionales o egoístas. Un ejemplo sería la ola de desregulación que tuvo lugar en los Estados Unidos a finales de los 70, donde muchos miembros del Congreso que apoyaron las políticas de desregulación lo hicieron sabiendo que perjudicaría seriamente a sus intereses y deseos de reelección. Esto pone de relieve el hecho de que la política democrática coherente de cualquier tipo es posible solo en la medida en que la racionalidad económica no colonice la política en cuyo ámbito se mantengan otros tipos de racionalidad. Esta necesidad de mantener la racionalidad económica fuera de la política fue reconocida hace mucho tiempo por Smith en su clásico estudio sobre La riqueza de las naciones, y ha sido retomada por autores contemporáneos del ámbito de la sociología política tan reputados como el ya citado Robert Dahl (1992). El desafío práctico es cómo asegurar los beneficios de la búsqueda libre de egoísmo en la economía evitando los peligros políticos así generados. En otro importante trabajo de Smith (2010), La teoría de los sentimientos morales, éste argumentó el cultivo de un tipo de comportamiento muy diferente: un reino de lo ético en el cual el espectador imparcial podría promocionar, al tiempo que restringir, su propio interés. Desgraciadamente, Smith murió antes de que pudiera desarrollar el relato completo de los principios generales del derecho y del gobierno prometido al final de la teoría de los sentimientos morales, en donde podría haber explicado cómo podría lograse tal 
mejora ética. Con todo, es posible pensar que esta mejora ética radica en la racionalidad comunicativa y que el alcance y necesidad de esta aumenta a medida que la sociedad evoluciona hacia formas más complejas. La racionalidad comunicativa sugiere a su vez un modelo distintivo de democracia, que es discursivo o deliberativo en carácter, y no un mero mecanismo para la agregación de preferencias individuales.

\subsection{De la racionalidad económica a la racionalidad comunicativa}

Según Jürgen Habermas (1985), inspirado en Max Weber, la modernidad trae consigo un potencial creciente para el ejercicio de dos tipos de razón: la instrumental y la expresiva, o comunicativa. Racionalidad no es, así pues, mera instrumentalidad, como tantas voces presuponen. Muchos críticos de la modernidad, entre los que se encuentran Weber, Horkheimer y Adorno, ya advirtieron de las consecuencias nefastas de ese reduccionismo. Weber se hacía eco de la "noche polar de oscura y gélida dureza", mostrando que el triunfo de la racionalidad instrumental se manifiesta en las estructuras burocrático-autoritarias públicas y privadas, en el que el único tipo de interacción interpersonal se sustenta en las órdenes de arriba-abajo y en la manipulación. Habermas argumenta que estos críticos de la modernidad lo que están sugiriendo es el potencial que existe para el surgimiento y la consolidación de un segundo y más amable tipo de racionalidad, la comunicativa, con características diferentes a la instrumental y organizada en torno a la comunicación humana en vez de en torno a la estrategia. Acción comunicativa que se orienta al entendimiento recíproco y la coordinación de las acciones. La política es inconcebible sin la acción comunicativa, ya que no se trata de la interacción de actores estratégicos jugando el uno contra el otro a juegos de suma cero. De modo que la racionalidad comunicativa puede definirse en términos de interacción lingüística competente, libre e informada, en ausencia de estrategias, jerarquías, engaños y autoengaños. Como tal, es una propiedad de colectividades, y no de individuos aislados, como confunden los teóricos de la elección racional. Es una racionalidad que avanza, aunque nunca plenamente realizada, junto con "estructuras modernas de la conciencia" y la decadencia del mito, la religión, la superstición y el apego a la tradición. Este tipo de racionalidad genera interacciones competentes, reflexivas y críticas propias de individuos sociales. Los individuos no viven en el aislamiento social; sus acciones e interacciones pueden mostrarse razonables y, dependiendo de las condiciones sociales en que se muevan, podrían regirse en función del lugar que ocupen en sus redes de relaciones políticas. De modo que la racionalidad tiene aspectos cognitivos, morales y subjetivos, no sólo instrumentales. En consecuencia, los desarrollos de las cosmovisiones, posiciones éticas e identidades personales contribuyen a constituir la identidad individual desde la cual se expresa la racionalidad. Además, la racionalidad significa la competencia para decidir cuándo es apropiado actuar instrumentalmente, conforme a las normas sociales, o comunicativamente, como un sujeto expresivo con capacidad de juzgar estas cualidades en los demás. Tal competencia comunicativa es, entonces, una cuestión de intersubjetividad y de interacción social. Y si esa interacción de produce en entornos descentralizados, existe potencial para incorporar la ética al discurso político, saliéndose del paradigma de la elección racional. Pues aunque en la deliberación política existe el desacuerdo, es posible siempre alcanzar compromisos sobre los diferentes intereses y sensibilidades.

La racionalidad instrumental tiene su lugar apropiado en la economía, la ciencia, la tecnología e incluso política, y de hecho desde su perspectiva se han alcanzado logros en el desarrollo social. Ahora bien, también en esos y otros ámbitos la racionalidad instrumental necesita ser modulada por la racionalidad comunicativa. Uno de estos ámbitos es la política, 
en donde el comportamiento meramente instrumental de maximización de intereses conduce a situaciones indeseables. La cuestión, entonces, reside en evitar estos resultados indeseables afirmando la preeminencia de la racionalidad comunicativa. Para ello es preciso poner límites al egoísmo tratando de incluir los valores en el discurso público racional y, resaltando un tipo diferente de interacción política. La deliberación pública puede conducir a la postergación de algunas preferencias privadas que no se sostendrían ante el escrutinio público, incluso a los ojos de quienes las ostentan. Así, es posible reducir la gama de opciones en un proceso de elección colectiva de manera que la deliberación puede promover el surgimiento de una voluntad general a partir de la valoración de las diferentes dimensiones que componen la decisión, en cada una de las cuales habrá que esperar a encontrar una posición común. Además, la deliberación no sólo aumenta la información, sino que, en cierto modo, altera los intereses y preferencias iniciales.

En definitiva, lo que está en juego en el encuentro de la racionalidad económica y comunicativa no es sólo una definición de la política y la democracia. Si verdaderamente queremos desterrar de la vida política las sombrías predicciones de análisis de la elección racional, una concepción liberal de la democracia será insuficiente. Para los liberales, la idea de democracia de preferencias agregadas, que se forman de acuerdo a los postulados de la economía neoclásica, han desembocado en las proclamas del Estado mínimo, o del gobierno tecnocrático, de expertos y gestores de lo público, cual si fuera privado. Por su parte, la racionalidad comunicativa apunta a una democracia más auténtica. La clase de democracia consistente con la racionalidad comunicativa y capaz de superar la problemática política interpretada por los teóricos de la elección racional, es la discursiva o de carácter deliberativo. Su esencia es la amplia y libre discusión sobre los puntos de conflicto orientados a algún tipo de acuerdo, y en esa discusión se pueden modificar, y no sólo agregar, las preferencias individuales.

\section{4. ¿ES POSIBLE MÁS Y MEJOR DEMOCRACIA?}

"We live in financial times", anuncia uno de los periódicos de cabecera del régimen capitalista de libre mercado triunfante (el Financial Times). En efecto, vivimos una época capitalista en la que la gama de modelos económicos plausibles parecen reducirse al capitalismo desregulado en el que se están convirtiendo los Estados de bienestar, nacidos a rebufo del paradigma keynesiano en el contexto de la Gran Depresión, la II Guerra Mundial y el temor al avance del poder soviético. Pero también vivimos en una época de predicamento democrático, en la que cualquier líder o activista político afirma no ser otra cosa que un demócrata. La democracia es lo que todos decimos querer, pero el capitalismo es lo que todos tenemos. La democracia capitalista no es una combinación fácil, feliz, ni siquiera sostenible. Este epígrafe explora someramente las perspectivas de la democracia frente a los riesgos y deterioros generados por la economía política capitalista (Naredo, 2010). Trata de identificar también que vías democráticas merece la pena perseguir con el fin de paliar esos riesgos. Históricamente, el avance del capitalismo ha sido correspondido por el avance de la democracia, por diversas razones, alguna de las cuales señalaremos. Pero, en los tiempos presentes, es muy cuestionable la contribución del capitalismo a la democracia. Ello es así porque los Estados en las economías capitalistas son cada vez menos democráticos en la medida en que las políticas públicas se formulan e implementan siguiendo los dictados de la necesidad de competir y crecer en una economía política transnacional globalizada. La culminación en la ilimitada movilidad del capital a través de las fronteras nacionales significa 
que las políticas públicas de los Estados nacionales se vean limitadas por temor de disgustar a los inversores actuales o potenciales, en la medida que las arcas públicas se ponen en sus manos, al dejar de controlar la emisión de moneda y aplicar políticas fiscales regresivas. En el estado actual del capitalismo, los gobernantes dan por hecho que la soberanía popular no debe, o no puede, interponerse en el camino del mercado. Los tratados de libre comercio sustentados en la ideología liberal, el racionalismo económico y un agresivo individualismo, se despliegan para obstruir cualquier democratización profunda y erosionar los logros democráticos existentes. Ante esta situación parece lógico pensar que la respuesta democrática necesita ser multidimensional y a menudo poco convencional. Esto nos lleva a subrayar que cabe la posibilidad de que las perspectivas para la democracia en tiempos capitalistas sean mejores, sin embargo, en la sociedad civil que en las instituciones formales del gobierno representativo. Por lo mismo, pensamos que las nuevas fórmulas democráticas puedan ensayarse mejor en los microespacios (ciudades, barrios, vecindarios; lugares de trabajo y de ocio) que en los niveles nacionales o transnacionales. Bien es verdad que ningún proyecto democratizador puede renunciar a extender la democracia a todo nivel, y a todo ámbito, de la vida social. Pero la situación actual hace más viable, a corto y medio plazo, el fomento de la innovación democrática pueda ser más admisible, y más inmediata, en esos microespacios.

En los actuales regímenes democráticos, la economía capitalista tiene relaciones complejas con la democracia, hasta el punto que difícilmente se soportan. Por una parte, una economía capitalista debe crecer y acumular o, de lo contrario, verse abocada a una recesión económica. Y una democracia que no persiga cotas de mayor democratización, centrándose, por ejemplo, en temas de gestión, genera un empobrecimiento de la vida política (Arendt, 1958). Digamos, con Anthony Downs, que la democracia es un proceso dinámico de gobierno e incluso de vivir en general, no una construcción institucional estática, lo que lleva a subrayar que los partidarios de la democracia deben continuamente esforzarse en cambiar no sólo sus formas, sino también sus significados a la búsqueda de una autenticidad democrática con las menores restricciones posibles. Entre los teóricos democráticos recientes, Arendt plantea especialmente esta posibilidad. En sus posicionamientos, esta autora está convencida de que la democracia auténtica requiere tiempo, compromiso y virtud, aspectos de los que sólo disponen pocos miembros en una sociedad. La democracia así concebida es un logro muy frágil, que conduce al elitismo y a la oligarquía, pues cuando se excluye a la mayoría de la sociedad de la atención cotidiana de los asuntos públicos, se dejan estos en manos de los administradores, los cuales acaban siendo una amenaza para la propia democracia. Un ejemplo paradigmático son las instituciones diseñadas para situarse en los márgenes de los límites al control democrático, tales como los bancos centrales, los servicios de inteligencia, las organizaciones militares y autoridades económicas transnacionales como la Organización Mundial del Comercio o el Fondo Monetario Internacional.

Así las cosas, la democracia participativa y deliberativa vendría a resituar al ciudadano dentro del ideal según el cual la democracia es fundamentalmente un demos que ejerce la soberanía directamente. De este modo, el ciudadano debería participar en los procesos de toma de decisiones públicas o, al menos, debería tener el poder de ratificar o rechazar las decisiones tomadas en su nombre por sus representantes. Y es en este punto donde se hace preciso diseñar un nuevo marco filosófico-político que permita formular una nueva teoría de la democracia que restaure el concepto a su concepción originaria, de manera que se puedan encontrar vías alternativas que permitan dar respuesta al antiguo ideal de participación directa, deliberativa e igualitaria, conforme a las realidades de las actuales naciones estado. 
En un plano contextual, aquí habría que decir que los modernos estado-nación disponen de mayor capacidad para realizar el ideal de democracia que la Atenas antigua, puesto que las sociedades actuales (las occidentales al menos) tienen a su disposición la infraestructura material, tecnológica, socio-política, educativa e institucional para hacer frente a los factores que contribuyeron a pervertir la idea originaria de democracia. Estas infraestructuras e instituciones, junto con una voluntad popular democrática, pueden restablecer una verdadera democracia reconduciéndola a su idea original

La idea de una democracia participativa semejante fue animada ya en la década de los sesenta y setenta del siglo pasado por Pateman y MacPherson. Los dos compartían además una mayúscula preocupación: que la democracia había sido jibarizada por la democracia liberal (Pateman, 1970; MacPherson, 2005). El foco de ambos se situaba en la cuestión de la democracia en una "sociedad economizada". En el caso de Macpherson, interesado por los problemas del control democrático de la economía, y, en el caso de Pateman, concernida por las relaciones laborales. En una línea análoga, pero ya en la década de los 80, Benjamin Barber (2004) se hacía eco de la necesidad de una forma de democracia más participativa, aunque sin mostrar interés por el control democrático de la actividad económica. Centrado más en los aspectos de soberanía colectiva, Barber proponía un sistema de referendos también a nivel nacional, de manera que se empoderara al ciudadano para participar en los procesos de toma de decisiones en el nivel macro en determinadas ocasiones, esperanzado en que mayores cotas de democracia política conducirían a mayores niveles de democracia económica.

En cualquier caso, esta imagen de la democracia deliberativa está comprometida con la existencia del gobierno representativo. Lo que busca es hacer la actual democracia representativa más deliberativa, más debatida, más participada. De modo que la democracia deliberativa es un ideal práctico que puede mejorar el ejercicio democrático a partir de la luz de una moral de inclusividad, con el fin de mejorar el rendimiento de cuentas por parte de los representantes. En este sentido, la misión de la democracia deliberativa sería resolver la brecha entre la ciudadanía y sus representantes, ofreciendo así una solución a la crisis de la democracia liberal y, entendida de esta manera, la democracia deliberativa no debería ser considerada como una variante de la democracia directa, sino como una teoría suplementaria de la concepción liberal democrática. Claro está, en el bien entendido de que el objetivo de la deliberación es contribuir a un proceso de toma de decisiones más participado y contrastado que el que proporcionan las vigentes instituciones representativas. Estas teorías de democracia deliberativa se adecuan, pues, a principios liberal democráticos, ya que las decisiones y políticas públicas seguirán siendo diseñadas e implementadas no por los ciudadanos, sino por los cargos electos y las burocracias. Siendo así, los juicios consensuados, o los veredictos colectivos, alcanzados por los ciudadanos en contextos deliberativos no tendrían el estatus de decisiones, leyes o políticas obligatorias, sino, más bien, el de sugerencias o recomendaciones que ser harían llegar al legislador para ser tenidas en cuenta en el proceso de elaboración de leyes y políticas públicas, incardinándose la deliberación en el proceso de influir a los representantes. Esto en lo que concierne al nivel micro (sectorial o territorial), donde los ciudadanos pueden reunirse físicamente para deliberar, mientras que en el nivel macro puede conducir a que los decisores públicos justifiquen las decisiones que toman apelando a criterios de razón que tomen en consideración criterios delimitados por valores como la libertad, la igualdad y el sentido de la comunidad, de manera que las decisiones o políticas públicas puedan ser aceptadas por todos los ciudadanos y, así, ganen en legitimidad. Por ello, resulta de sumo interés que la idea de justificación pública se sitúe en el núcleo del concepto de democracia deliberativa, de manera 
que los ciudadanos tengan la posibilidad de contestar a las justificaciones ofrecidas por los decisores públicos. Y, por añadidura, que los decisores públicos estén sujetos a justificación pública en razón de consideraciones morales y epistémicas en contra de los poderes que la economía ejerce sobre una democracia que para sobrevivir depende de su financiación. Igualmente sería posible que, en niveles macro, los desarrollos en las telecomunicaciones facilitaran gradualmente la deliberación. Esta democracia que busca inventarse es opuesta a la denominada democracia de audiencia, donde los ciudadanos no son considerados con capacidad de deliberación, sino como oyentes pasivos de las deliberaciones que tienen lugar entre las élites.

\section{DE LA DEMOCRACIA LIBERAL A LA DEMOCRACIA DELIBERATIVA}

Parece razonable admitir que la teoría normativa más influyente de la democracia que ha emergido durante las dos últimas décadas lleva el sello de la democracia deliberativa. Esta teoría se presenta en diversas formas, aunque todas ellas se sustentan en las obras de Jürgen Habermas y de John Rawls, quienes han liderado los esfuerzos para reformar las bases normativas de la democracia con el fin de rehabilitar la noción de deliberación pública. Para Habermas, en la democracia deliberativa se articularía el concepto de soberanía popular según el cual el último recinto de legitimidad serían las decisiones colectivas derivadas de una deliberación pública, que se concibe en términos de un conjunto de procedimientos en verdad algo idealizados (Habermas, 1985, 1998, 1999). Por su parte, la formulación rawlsiana de la democracia deliberativa complementa la habermasiana en aspectos claves más allá del procedimentalismo, estando en deuda con la tradición del constitucionalismo liberal y del contrato social. Habermas defiende una concepción de democracia deliberativa que se sitúa en un punto intermedio entre liberales y comunitaristas, con una orientación igualitarista. Como buen representante de la Escuela de Frankfurt, su aproximación a la teoría democrática se encuentra dentro de un marco más amplio de la teoría crítica neomarxista, y es compatible con sus investigaciones anteriores, iniciadas en la década de 1960, en temas tales como la esfera pública, la crítica de la ideología, la racionalidad comunicativa y la ética discursiva. Sin duda, el modelo de Habermas de democracia deliberativa pretende proporcionar una base racional para el ideal democrático apelando a una cierta concepción de la deliberación pública. La conducta de las instituciones sería legítima y racional en el caso de que sus decisiones fueran el resultado de un procedimiento de razonamiento público en una situación ideal de habla. Por tal entiende una situación hipotética abierta, de comunicación igualitaria, orientada hacia el consenso racional (es decir, fundado en una apelación a los argumentos y discusiones superiores que se atengan a los intereses generales, y no en la fuerza de la autoridad). Para ser considerada como racional, la participación democrática en la toma de decisiones colectivas no debe estar orientada con criterios egoístas o estratégicos, sino por procesos colectivos para la formación tanto de las opiniones como de las voluntades que atiendan a criterios de generalización. Y es aquí donde se sitúa la distinción habermasiana entre la acción comunicativa y la acción estratégica, así como los modos de racionalidad adecuada a cada una de ellas. De este modo, la racionalidad instrumental o estratégica (la capacidad de identificar medios eficaces de realizar teniendo en cuenta los extremos) difiere en aspectos importantes de la racionalidad comunicativa que busca el entendimiento y el consenso. Se orienta exclusivamente por la "fuerza no forzada" de argumentos superiores y está libre de la otros factores, particularmente de la ideología o 
"distorsión sistemática" de nuestras prácticas lingüísticas y sociales. Cabe suponer, por tanto, que desde la perspectiva de Habermas, las deliberaciones democráticas son racionales y legítimas en tanto se ajusten a determinadas normas de la argumentación, tales como el principio de universalización. Con este procedimiento, Habermas la transforma la idea kantiana de universalización (Kant, 2000), en una pragmática trascendental como teoría de la argumentación. Según la concepción habermasiana de la "razón pública", los principios son válidos siempre que sean capaces de generar consenso voluntario en el marco de las condiciones del discurso racional.

Sea como fuere, la legitimidad y racionalidad inherentes al modelo deliberativo de la democracia requiere que las instituciones estén dispuestas a aceptarla, de modo que se tenga en consideración el interés común de todos los procesos de deliberación colectiva y que ésta sea realizada racionalmente entre individuos libres e iguales. El principio rector de la deliberación colectiva es que los procedimientos precisan un debate político en condiciones igualitarias, públicas e inclusivas, libres de coerción, racionalmente motivadas, e imparciales, con respeto a las formas de la argumentación (Habermas, 1985). Como es evidente, lo mismo Habermas que Rawls diferencian entre los consensos racionales relativos a los acuerdos fácticos y los que se refieren a las condiciones de dicho consenso (Habermas, 1999). Podemos suponer, entonces que, para Habermas, existen obstáculos a la deliberación democrática, pero son meramente empíricos y, por consiguiente, eliminables. La deliberación puede ubicarse, así, lo mismo en órganos parlamentarios que en redes informales de la esfera pública. En consecuencia, Habermas reclama una extensión radical de la esfera pública para favorecer la deliberación a las redes informales de comunicación, y aplaude también los nuevos movimientos sociales en los que puede concretarse el ejercicio de la democracia deliberativa. En cambio, Rawls difiere de la concepción de democracia deliberativa de Habermas en un aspecto importante, cual es el rechazo de la concepción procedimental en favor de una concepción sustantiva de la democracia liberal constitucional propia de la tradición contractualista, donde los derechos humanos sirven como limitaciones inviolables en el proceso democrático. Además, el Rawls constitucionalista afirma en su obra sobre el liberalismo político que el ejercicio del poder político es correcto cuando es ejercitado de acuerdo con una Constitución.

No importa cuál sea la perspectiva seguida, deliberación implica la posibilidad y capacidad de los ciudadanos para poder comunicarse acerca de las decisiones colectivas en términos que sean susceptibles de aceptación reflexiva por parte de los sujetos a los que afecta la decisión. La idea fundamental de legitimidad democrática es que la autorización para ejercer el poder del estado debe surgir de las discusiones y decisiones colectivas de los miembros de una sociedad que se rigen por ese poder. Luego habrán de ser canalizadas por medio de instituciones sociales y políticas, diseñadas para reconocer, y ejercer, la autoridad colectiva. De manera similar, Habermas, en sus escritos sobre la democracia deliberativa y la ética del discurso, sugiere que, para llegar a hipotéticos acuerdos, sería preciso buscar un punto intermedio entre lo que racionalmente se debería aceptar y los que están de acuerdo. Por supuesto, un partidario de las concepciones agregativas o utilitaristas, en las que se sustenta la práctica política actual, argüiría que sus políticas se legitimarían si son aceptadas por una mayoría de ciudadanos. Pero no se trata tanto de una cuestión de mayorías que pueden rebajar la idea original de deliberación, mientras los ciudadanos acepten una política determinada, cuanto que el ciudadano la quiera, algo que parece ignorar la reflexión que hace Rawls al elaborar su teoría de la justicia que, en cierto modo, se asemeja a Hobbes en su Leviatán, al afirmar éste que las personas reales podrían convenir a esas políticas impuestas por otros. Aquí interviene una consideración de diferente orden, cual es si los ciudadanos 
están de acuerdo, o lo estarían en caso de tener la oportunidad de opinar, sobre los asuntos de interés público.

Aunque las demandas de deliberación pública y de participación efectiva en las políticas democráticas ha sido recurrente en la teoría política democrática liberal, lo cierto que es una llamada que ha prosperado poco, y que en la actualidad se encuentra altamente formalizada y restringida a la participación de sectores específicos. En sus formulaciones, tanto Habermas como Rawls claman, además, para que los asuntos públicos se traten a través de una deliberación en la que se pongan en juego las diversas creencias, valores y actitudes que caractericen nuestra particularidad como individuos y como miembros copartícipes de una cultura. La paradoja es que lo que cuenta como una razón convincente en la deliberación política está restringida a un rango bastante estrecho de elocuciones en relación a lo que normalmente debería ser una argumentación democrática. En la mayoría de las formulaciones se limita a juicios que se ajustan a ciertos procedimientos ideales o reglas argumentativas que son difíciles de realizar. La formalización y la racionalización del concepto de deliberación pública hacen realmente cuestionable si las democracias contemporáneas respetan la genuina idea democrática de participación igualitaria en el proceso de toma decisiones por aquellos que van a sufrir sus consecuencias. En todo caso, las versiones de democracia deliberativa formuladas por Rawls y Habermas resultan casi tan racionalistas como idealistas. Sus filosofías políticas, normativas, no son fácilmente integrables en las prácticas de las democracias actuales, y tampoco son sustentos sencillos para poner en marcha un proyecto empírico de innovación democrática.

Abstrayendo el meollo de lo dicho hasta aquí, la deliberación es una forma del discurso argumentativo, y por tanto ha de ser bien ordenada, formalista, inclusiva e igualitaria. Presupone una orientación común hacia intereses generalizables, la renuncia a la acción estratégica y a los particularismos individuales y cortoplacistas, así como una aceptación básica de las reglas del discurso racional. También implica el compromiso porque la justicia reemplace la voluntad de poder en las deliberaciones. Por parte de los políticos profesionales se requiere una renuncia a la acción estratégica e, incluso, a las payasadas habituales de la política partidista. Por lo mismo, también requiere un grado avanzado de buena voluntad, tolerancia y respeto por las diferentes posiciones y diferencias, así como la aceptación de la legitimidad y la racionalidad de las decisiones tomadas por mayoría incluso en caso de no estar de acuerdo con las decisiones mayoritarias. Esta forma de deliberación presupone no sólo una estructura institucional adecuada y un compromiso con el discurso igualitario, sino también una ausencia de agendas ocultas o privadas, un conocimiento de las pruebas pertinentes, una capacidad de discernir los diferentes grados de relevancia y de identificación de sofismas. Desde otro punto de vista, la deliberación presupone un determinado nivel de conocimiento y autoconocimiento, un conjunto de valores más o menos estable, un conocimiento de la variedad de opciones y de lo que significan, además de la capacidad de discernir acerca de la opción más inteligente. Como es lógico, las propuestas deliberativas suelen albergar un fuerte componente idealista, y no siempre es fácil traducirlo en términos de práctica política. Tal vez no es casualidad que un defensor de la democracia deliberativa como Habermas prefiera limitar su atención a las grandes cuestiones de epistemología política, más que a cuestiones de calado más pragmático. Resulta mucho más cómodo, menos problemático. Otras dificultades del modelo deliberativo se refieren los mecanismos que hayan de desplegarse para garantizar las condiciones de imparcialidad, igualdad e inclusión, argumentación racional, acción comunicativa e incluso buena voluntad, así como la prioridad de la justicia sobre el poder. Estos trances, que Habermas sortea afirmando que 
son contingentes, empíricos, requieren gran imaginación y mucha voluntad para ser superados. La respuesta de Habermas está preñada de optimismo, pero es el optimismo de los racionalistas y de la utopía hacia la que hay que tender y que debe actuar como idea reguladora en términos kantianos. Pero, para ser creíble, la teoría de la democracia deliberativa no debe perder el contacto con la práctica que se observa y realiza en el discurso político existente. El enfoque teórico de la democracia deliberativa aporta consideraciones interesantes desde el punto de vista de concepciones idealizadas o racionalizadas para el dialogo, pero, a la postre, hay que decidir si uno cree en las formas ordinarias de interacción política y en el proceso democrático o no.

Hoy por hoy, hablar de la democracia como política de la deliberación es más que un hecho cierto, una aspiración, pero deseable y realizable. Tal vez deba ser más un eros político, que un ideal normativo en su sentido habitual. Lo que no es posible hacer es perder el contacto con la práctica de la democracia realmente existente. El ideal democrático debe ser aplicable en la práctica para que sea útil. Si hay un sentido en el que la democracia es de hecho algo "por venir", como diría Derrida, tiene que ser aquí y ahora. La democracia deliberativa es, como orientación, completamente inobjetable, y existe una geografía de oportunidades vitales donde puede darse, como se señalará posteriormente. Así considerada, la democracia deliberativa no tiene que ser propiamente una alternativa a la democracia liberal, como muchos postulan. Tampoco tiene por qué circunscribirse al papel de un ideal digno. Antes bien, puede ser un instrumento para el rescate de la democracia liberal, para que recupere su espíritu. Confiamos que esta apelación a la deliberación sirva también para recordar a los liberales los principios revolucionarios, emancipatorios y participativos que radican en la concepción de la política liberal primigenia, del liberalismo que surgió como la forma política dominante de la modernidad y, con bastante rapidez a partir de entonces, ha seguido un proceso de espeluznante degeneración. Como vuelta al espíritu originario, o como correctivo de lo que hay, la democracia deliberativa proporciona elementos de utilidad para la profundización democrática. Bien es cierto que, en la medida que las propuestas deliberativas suelen rechazar el liberalismo constitucional, sitúan los derechos humanos en un plano contingente.

La democracia deliberativa viene a reafirmar la necesidad de justificar las decisiones tomadas por los ciudadanos y sus representantes. Ambos tienen que argumentar las leyes que les obligan con respecto a los demás. En una democracia, los líderes, por lo tanto, deben dar razón de sus decisiones y responder a las razones que los ciudadanos dan a cambio. Pero no todos los problemas, todo el tiempo, requieren deliberación. La democracia deliberativa deja espacio para muchas otras formas de toma de decisiones, siempre y cuando el uso de estas formas esté justificado en algún momento de un proceso deliberativo, y sus decisiones sean cuestionables y reversibles. Su primera y más importante característica sería entonces el dar cuenta y razón. Y la fundamentación moral para dar cuenta y razón es común a muchas concepciones de la democracia. Ello implica que los ciudadanos deben ser tratados no como meros súbditos de las normas legales, o sujetos pasivos, sino como agentes autónomos capaces de participar en el gobierno de su propia sociedad, directamente o a través de sus representantes. De ser así las cosas, en la democracia deliberativa los ciudadanos participan presentando razones o exigiendo a sus representantes que lo hagan, con el fin de justificar las leyes bajo las cuales deben vivir juntos. Las razones están encaminadas tanto para producir una decisión justificada como para expresar el valor del respeto mutuo. No es suficiente con que los ciudadanos hagan valer su poder a través de la negociación por medio de los grupos de interés con los que se sientan identificados, o al votar en elecciones. Las afirmaciones de poder y las manifestaciones de voluntad son desde luego una parte clave de la política 
democrática, pero tienen que ser justificadas por la razón discursiva, por el debate. Cuando la razón principal que ofrece el gobierno para ir a una guerra resulta ser falsa, engañosa, no sólo es la justificación para la guerra lo que debe ser puesto en cuestión, sino también su falta de respeto a los ciudadanos.

Otro aspecto importante de la democracia deliberativa es que los datos y las razones proporcionados en el proceso de discusión pública deben ser accesibles a todos los ciudadanos a los que se dirigen. Para justificar la imposición de su voluntad, sus conciudadanos deben dar razones que sean comprensibles para cualquier sujeto que se vea afectado por la decisión. Este es un hecho capital, pues sin "comprensión esclarecida", como sostenía Dahl (1992) no es posible decidir por uno mismo y ejercer su derecho a participar de las decisiones colectivas sobre los asuntos comunes.

\section{CONSIDERACIONES FINALES}

Hubo un tiempo en el que la racionalidad económica luchó contra las fuerzas de las jerarquías orgánicas al servicio de los privilegios aristocráticos y religiosos. En esa lucha, la democracia y la racionalidad económica resultaron compatibles y complementarias, aunque algunos observadores tan clarividentes como Adam Smith fueron capaces de discernir algunos elementos contradictorios. La situación hoy día es muy diferente, pues el desarrollo y predominio de la racionalidad económica se ha desbridado y amenaza consumir cualquier modelo de democracia. El pensamiento neoclásico más destilado, cual son las teorías de la elección pública, ha admitido la imposibilidad de un orden político democrático fundamentado en un egoísmo racional sin restricciones. La implicación directa es que el capitalismo desaforado, y no el proletariado industrial, está enterrando la democracia. Sus sepultureros son actores individuales, más que colectivos, y están cavando una tumba diferente a la esperada. Al comportarse como los economistas neoliberales predican, y animados por la estela de gobernantes como Ronald Reagan o Margaret Thatcher, y sus herederos ideológicos, la acción confluyente de un número no muy amplio de individuos está socavando la concepción liberal de la democracia que dicen defender, pues la racionalidad económica que les guía es mortífera para la democracia liberal propia del ideal ilustrado. La interacción política implica acción comunicativa, y esta está ausente de los discursos economicistas, puramente estratégicos. Más aún, la racionalización económica mina la dimensión comunicativa de la política y, en consecuencia, la comunicación igualitaria entre los ciudadanos es progresivamente desplazada por el autoritarismo. Al final de este camino se encuentra la distopía liberal autoritaria de una sociedad individualista agresivamente vigilada por un estado altamente centralizado. En este sentido, no es coincidencia que la racionalización económica y la centralización estatal se comportasen como hermanas siamesas en la Gran Bretaña thatcheriana durante la década de los 80 del siglo pasado. Así está acaeciendo ahora con las políticas de recortes y reformas estructurales que vienen aplicando los gobiernos europeos como supuesto antídoto para la crisis económica. A la luz de las circunstancias, la esperanza para el futuro de la democracia en estos duros tiempos de capitalismo desaforado radica en la activación e institucionalización de la racionalidad comunicativa, y en la concepción de la democracia como deliberación pública, y no como vehículo de agregación de preferencias individuales. Creemos que esto no es un proyecto utópico. La deliberación es práctica ya arraigada en numerosos espacios de la interacción social, sobre todo en comunidades pequeñas (ciudades, pueblos, barrios; pero, también, 
asociaciones voluntarias, cooperativas de obreros o de empresarios,...). Con todo, para que estas iniciativas cuajen, es menester que surjan fuerzas canalizadoras de la interacción deliberativa. No cabe duda de que, en el actual curso de la relación de poderes, el propósito deliberativo resulta problemático cuando se aplica a las estructuras estatales. Aun así, ni el Estado ni los diseñadores de políticas públicas, a nivel estatal o supraestatal, debieran ignorar que existen otras concepciones de la política más allá de las concepciones autolimitantes impuestas por la racionalidad económica. A fin de cuentas, el desarrollo de la conectividad electrónica proporciona nuevos y poderosos medios para establecer nuevas formas de participación política a nivel macro, todavía inexploradas.

En pro del libre mercado, los Estados se vuelven frágiles respecto al desarrollo del bienestar común. Ello es así en la medida en que sus actividades y sus estructuras están condicionadas por imperativos propios de la racionalidad económica, y de los intereses materiales de unas poderosas minorías. Este hecho tiene su correlato en la existencia de limitadas posibilidades para la innovación democrática tanto hacia afuera (sistema internacional) como hacia adentro, hacia sus propias sociedades. Y en ese sistema es donde deben mantenerse a flote. En el pasado esto significaba, sobre todo, hegemonía y seguridad militar, pero, cada vez más, la supervivencia depende de variables económicas. Así, en el orden económico transnacional vigente se han consolidado los movimientos libres de bienes, servicios, finanzas, capital y (menos) personas a través de las fronteras nacionales. Este orden, y las instituciones que lo supervisan, como el Fondo Monetario Internacional, el Banco Mundial, las corporaciones multinacionales y los bancos que operan a nivel global, imponen enormes limitaciones a lo que todos los Estados (no solo los de mayor deuda pública) pueden hacer. Si bien es cierto que tienen capacidad para ejecutar iniciativas democráticas contra los dictados de la economía política internacional, conocen las consecuencias de desobedecer en la escena internacional. Así ocurre no solo con los países de la periferia, sino también con los centrales y, se supone, más prósperos.

Como se ha dicho, el capitalismo fue históricamente un aliado en el surgimiento de la democracia, pues los regímenes constitucionales liberales surgieron en el contexto de las economías capitalistas. Esto ha sido así porque el capitalismo generó una clase trabajadora que tiene más que ganar con la democracia y, por lo tanto, presiona hacia la democratización. Sin embargo, este tipo de desarrollo puede haber alcanzado su límite en los países capitalistas avanzados cuya clase obrera industrial está ahora disminuyendo. La universalización del mercado capitalista como la principal forma de organización económica está acompañada de una disminución de las respuestas colectivas para la solución de los problemas comunes. Aumenta, en cambio, el individualismo, lo cual tiene también consecuencias antropológicas: la transformación moral de los seres humanos que viven en sociedad, un lugar creado por expresiones individuales y, por tanto, un lugar de política y de ideales, pero del cual se pierde conciencia. Pese a estos y otros envites, el Estado sigue siendo la forma política dominante en el mundo contemporáneo y un instrumento fundamental para cualquier clase de transformación democrática. Y es posible actuar dentro de él, si no se pierde vista de la complejidad de sus cometidos e impedimentos.

Recapitulando lo expuesto, hay que subrayar, en primer lugar, que la idea de gobierno de la gente (el ideal del empoderamiento político de las personas) propuesto por la práctica y la filosofía política pre-liberales no es una noción inviable, aunque sí dificultosa. Como idea de gobierno del pueblo, la democracia se practicó con éxito en ciertos períodos, pero de corta duración, en espacios y demos muy localizados, como la antigua Atenas. Por su lado, la propuesta de Rousseau, puramente teórica, resulta insatisfactoria como referente, pues, aunque situaba el énfasis en la participación directa del ciudadano, limita su alcance a un 
pequeño cuerpo político agrario. De modo que la perversión de la idea original de democracia en la era pre-liberal puede ser achacada, en gran modo, a la escasez material, y a sus correspondientes deficiencias sociopolíticas y culturales. La culpa de la perversión de la idea original en la época liberal y en las sociedades liberal-democráticas se debe, en cambio, a los esfuerzos de quienes trataron de utilizar la democracia como una estrategia de estabilización, esto es, de procura de un orden beneficioso para los grupos sociales privilegiados, aquellos que demandaban seguridad para el libre funcionamiento de un mercado porque se encontraban posicionados en lugares preferentes para extraer el mayor provecho particular. Por eso instaron a una democratización limitada, presentada como una categoría de la idea de libertad, que era el principio rector del Estado liberal y de sus ideólogos del mercado libre. Fue precisamente en el marco de este proceso donde la democracia perdió su contenido moral, convirtiéndose en un simple método de toma de decisiones. Esta transformación fue guiada en el último cuarto del siglo XIX, y principios del $\mathrm{XX}$, por sectores sociales bien organizados de las clases de propietarios, así como por sus aliados, principalmente la élite intelectual de la burguesía, elaborando soflamas para satisfacer su deseo de proteger sus intereses y su estatus de privilegio ante los "elementos indeseables", esto es, las clases populares. No es exagerado afirmar, así pues, que la sociedad liberal, en sus etapas anteriores, no tuvo nunca una pretensión de democracia plena. El sufragio universal se aceptó a regañadientes, y se consideró como la cumbre de la excelencia democrática. Pese a ello, el problema subyacente de la concepción liberal-democrática es que se basa exclusivamente en la representación. La idea democrática se transforma entonces en mero gobierno representativo elegido popular y libremente. Esta forma política margina a los ciudadanos y transfiere los poderes de toma de decisiones legislativas y políticas públicas a manos de unos representantes que, con el tiempo, se configuran a modo de una clase aparte, a través de la cual sus miembros acceden al poder de forma "natural", compitiendo en elecciones y estableciendo alianzas con poderes económicos y mediáticos. Tanto es así que el gobierno representativo en los Estados liberales y democráticos liberales se funda en mantener a los ciudadanos alejados del negocio de gobernar. Por eso estos gobiernos representativos acaban siendo instrumentalizados por los grupos mejor organizados o con capacidad financiera, que tratan de utilizar el estado para sus propios propósitos. Lejos de empoderar políticamente a los ciudadanos, la versión liberal de la democracia persigue activamente desempoderarlos, recurriendo, si es menester, a argumentos de autoridad: deben gobernar los que (supuestamente) saben, es decir, los expertos.

Una visión muy distinta de la democracia a esta del racionalismo economicista propugnado por las clases propietarias y gestoras emerge, en cambio, si admitimos una perspectiva de racionalidad comunicativa, o una perspectiva contextualista, como las sugeridas por Habermas y Rorty, respectivamente. Entonces surge la posibilidad de una democracia deliberativa, y no meramente agregativa, que requiere la activa participación ciudadana y satisface los derechos de ciudadanía. Esta democracia deliberativa se modularía en función de los diferentes lugares en que se implantase. Tres serían las arenas posibles: la comunidad política (tanto nacional como supranacional y subnacional), la economía y la sociedad civil. Pensamos que, en el contexto europeo de gobiernos multinivel, los gobiernos locales constituyen un ámbito especialmente propicio para que los ciudadanos tengan la posibilidad real de involucrarse en procesos democráticos deliberativos. Máxime porque, como muestran sistemáticamente los datos del Eurobarómetro, la confianza de los ciudadanos en los gobiernos locales es superior a la que obtienen los gobiernos y los parlamentos nacionales. Este simple hecho pone de manifiesto la importancia de los 
gobiernos locales para la estabilidad del sistema político en la Unión Europea. Y pone asimismo de manifiesto el poderoso papel que las metodologías de democracia deliberativa pueden desempeñar con el fin de incluir la sociedad civil en el diseño e implantación de políticas públicas locales, reforzando la democracia directa (referendos, revocación de cargos de políticos locales y burocráticos, etc.), y la participación ciudadana (jurados ciudadanos, foros temáticos, consejos territoriales de barrio, e-democracia, etc.). Son horizontes perfectamente alcanzables con los que contribuir a construir, aquí y ahora, más y mejor democracia.

\section{BIBLIOGRAFÍA}

ARENDT, H. (1958). The Human Condition. Chicago: The Chicago University Press.

ARROW, K. (1950). "A Difficulty in the Concept of Social Welfare", en Journal of Political Economy, 58 (4): 328-346.

BARBER, B. (2004). Democracia fuerte. Córdoba: Almuzara.

BUCHANAN, J. y TULLOCK, G. (1993). El cálculo del consenso. Barcelona: Planeta Agostini.

COLOMER, J. M. (2001). Instituciones políticas. Barcelona: Ariel.

DAHL, R. (1992). La democracia y sus críticos. Barcelona: Paidós.

DEWEY, J. (1984). The Public and Its Problems. An Essay in Political Inquiry. Carbondale: Southern Illinois University Press.

ELSTER, J. (1990). El cambio tecnológico: Investigación sobre la racionalidad y la transformación social. Barcelona: Gedisa.

FOUCAULT, M. (1980). El nacimiento de la clínica: una arqueología de la mirada médica. Madrid: Siglo XXI.

FUKUYAMA, F. (1992). El Fin de la historia y el último hombre. Barcelona: Planeta.

FUKUYAMA, F. (1990). "¿El fin de la historia?", en Doxa, 1 (1): 3-12.

GARCÍA SANTESMASES, A. (1997). "Estado, mercado y sociedad civil". En F. Quesada (ed.) Ideas políticas y movimientos sociales. Madrid: Consejo Superior de Investigaciones Científicas, pp. 217-34.

GIL CALVO, E. (2013). Los poderes opacos: Austeridad y resistencia. Madrid: Alianza.

HABERMAS, J. (1975). Problemas de legitimación en el capitalismo tardio. Buenos Aires: Amorrortu.

HABERMAS, J. (1985). Conciencia moral y acción comunicativa. Barcelona: Península.

HABERMAS, J. (1998). Facticidad y validez. Madrid: Trotta.

HABERMAS, J. (1999). Teoría de la acción comunicativa I, Madrid: Taurus.

HIRSCHMAN, A. (1970). Exit, Voice and Loyalty. Cambridge: Harvard University Press.

HUNTINGTON, S. (1996). El choque de civilizaciones y la reconfiguración del orden mundial. Buenos Aires: Paidós.

JUDT, T. (2010). Algo va mal. Madrid: Taurus.

KANT, I. (2000). Zum ewigen Frieden. Werke, Akademie Ausgabe, vol VIII. Berlín: Meiner Verlag.

MACPHERSON, C. B. (2005). La teoría política del individualismo posesivo: de Hobbes a Locke. Madrid: Trotta.

NAREDO, J. M. (2010a). "El modelo inmobiliario español y sus consecuencias", en Boletín $C F+S$, 44: 13-27.

NAREDO, J. M. (2010b). Raíces económicas del deterioro ecológico y social. Más allá de los dogmas. Madrid: Siglo XXI.

NISKANEN, W. A. (1974). Bureaucracy and Representative Government. New Brunswick: Transaction Publishers.

NOZICK, R. (1974). Anarchy, State, and Utopia. Nueva York: Basic Books.

OFFE, C. (1987). "Democracy against the welfare state?: Structural foundations of neoconservative political opportunities", en Political Theory, 15 (4):501-537.

PATEMAN, C. (1970). Participation and Democratic Theory. Cambridge: Cambridge University Press. 
POLANYI, K. (1989). La gran transformación: Crítica del liberalismo económico. Madrid: La Piqueta. POPPER, K. R. (1992). La sociedad abierta y sus enemigos. Barcelona: Planeta Agostini.

PRZEWORSKI, A. (1991). Democracy and the market: Political and economic reforms in Eastern Europe and Latin America. Cambridge: Cambridge University Press.

QUESADA, F. (2006). Sendas de democracia: entre la violencia y la globalización. Rosario: Homo Sapiens.

RAWLS, J. (2006). Teoría de la justicia. México: Fondo de Cultura Económica.

RORTY, R. (1989). Contingency, Irony, and Solidarity. Cambridge: Cambridge University Press.

ROSTOW, W. (1990). The stages of economic growth: A non-communist manifesto. Cambridge: Cambridge University Press.

ROUSSEAU, J. J. (2004). El contrato social. Madrid: Akal.

SARTORI, G. (2003). ¿Qué es la democracia? Madrid: Taurus.

SCHUMPETER, J. (1996). Capitalismo, socialismo y democracia, Vol. II. Barcelona: Folio.

SMITH, A. (1958). Investigación sobre la naturaleza y causas de la riqueza de las naciones. México: Fondo de Cultura Económica.

SMITH, A. (2010). Teoría de los sentimientos morales. México: Fondo de Cultura Económica.

WEBER, M. (1998). La ética protestante y el espíritu del capitalismo. Madrid: Akal.

\section{Breve currículo:}

\section{Ángel Iglesias}

Profesor Titular de Ciencia Política y de la Administración de la Universidad Rey Juan Carlos. Ha sido Profesor Visitante en varias universidades europeas y norteamericanas. Es doctor en Ciencia Política y de la Administración así como Licenciado en Derecho por la Universidad Complutense de Madrid, es así mismo Licenciado en Sociología y en Filosofía por la UNED. Ha sido Investigador e Investigador principal en varios proyectos de convocatorias públicas nacionales e internacionales teniendo por objeto de estudio la democracia y gestión local en España y en Europa y ha publicado sus resultados en monografias, obras colectivas y artículos y ensayos en revistas nacionales e internacionales. 


\section{Roberto-Luciano Barbeito}

Profesor en la Universidad Rey Juan Carlos y miembro del Grupo de Investigaciones y Estudios Sociales Avanzados (GIESA-URJC). Sociólogo y politólogo por la Universidad Complutense, fue galardonado con el Premio Nacional Fin de Carrera. Ha sido Director Técnico del Instituto de Opinión Pública e Investigaciones Sociales Tábula-V, y ha trabajado además como analista social y político en Radio España. Investigador invitado en las universidades de Oxford (Reino Unido) y de Dublín (DCU) (Irlanda). Ha participado en una treintena de investigaciones sociológicas que han dado lugar a diversos libros y artículos científicos. Sus líneas de investigación actuales incluyen el análisis sociopolítico, con especial énfasis en las bases sociales de la democracia, y la metodología de la investigación social.

*Este texto se enmarca dentro del Proyecto de Investigación IS 1207, financiado por la Unión Europea dentro de su Programa Marco vigente, bajo el título Local Public Sector Reforms: an International Comparison, subproyecto Innovaciones Democráticas en los Gobiernos Locales Europeos, del que es investigador principal para España Ángel Iglesias.

** El presente trabajo ha sido seleccionado de entre los presentados al XIX Congreso Nacional de Sociología en Castilla-La Mancha que, organizado por la Asociación Castellano-Manchega de Sociología se celebrará en Almagro (Ciudad Real) España, los días 7,8 y 9 de noviembre de 2014. 